P-ISSN: 2615-1723

E-ISSN: 2615-1766

April 2019
Jurnal Riset Pendidikan Dasar

02 (1), (2019) 74-80

Submitted: Januari, Accepted Maret, Published: April

\title{
PENGARUH TEKNIK MIND MAPPING TERHADAP KETERAMPILAN MENULIS PUISI SISWA SEKOLAH DASAR
}

\author{
Dina Dahliana \\ Pendidikan Dasar, Fakultas Ilmu Pendidikan Universitas Negeri Padang \\ Korespondensi. E-mail: dinadahliana23@gmail.com
}

\begin{abstract}
Abstrak
Penelitian ini bertujuan untuk meneliti Pengaruh Teknik Mind Mapping terhadap Keterampilan Menulis Puisi siswa di sekolah dasar. Penelitian ini adalah penelitian eksperimen jenis Quasi Experimental Design dengan rancangan Nonequivalent Control Group Design. Populasi dalam penelitian ini adalah seluruh siswa kelas V semester II. Pengambilan sampel dilakukan dengan teknik sampel jenuh (total sampling) yaitu kelas VB sebagai kelas eksperimen dan kelas VA sebagai kelas kontrol. Kelas eksperimen berjumlah 34 siswa dan kelas kontrol berjumlah 36 siswa. Kelas eksperimen diberi perlakuan dengan menggunakan teknik mind mapping dalam keterampilan menulis puisi sedangkan kelas kontrol tanpa menggunakan teknik mind mapping. Berdasarkan hasil pretest diperoleh nilai rata-rata kelas eksperimen 60 dan nilai rata-rata kelas kontrol 64,2. Dari hasil perbandingan kedua kelas sampel tersebut diperoleh perbedaan nilai sebesar 3,7, maka dapat disimpulkan tidak terdapat perbedaan yang signifikan nilai pretest kedua kelas, artinya kedua kelas memiliki kemampuan awal yang sama. Selanjutnya dilakukan pembelajaran yang menggunakan teknik mind mapping pada kelas eksperimen dan pembelajaran tanpa teknik mind mapping pada kelas kontrol. Setelah pembelajaran diberikan kemudian pada kedua kelas dilakukan posttest. Untuk kelas ekperimen diperoleh nilai rata-rata 82 dan untuk kelas kontrol diperoleh nilai rata-rata 77,5. Dari hasil pengujian hipotesis dengan taraf signifikan 0,05 diperoleh nilai signifikan sebesar 0,000 karena sig. $<\alpha$ maka hipotesis diterima, sehingga dapat disimpulkan bahwa terdapat pengaruh penggunaan teknik mind mapping terhadap keterampilan menulis puisi siswa di sekolah dasar.
\end{abstract}

Kata Kunci: Teknik Mind Mapping, Keterampilan Menulis, Puisi

\section{THE EFFECT OF MIND MAPPING TECHNIQUE ON POETRY WRITING SKILLS OF BASIC SCHOOL STUDENTS}

\begin{abstract}
This study aims to examine the effect of Mind Mapping Technique on Poetry Writing Skills of students in elementary school. This study was an experimental study of Quasi Experimental Design with Nonequivalent Control Group Design. The population in this study were all fifth grade students of class $V$. Sampling is done by saturated sample technique (total sampling), namely VB class as an experimental class and VA class as a control class. The experimental class consisted of 34 students and the control class consisted of 36 students. Based on the results of the pretest obtained the average value of the experimental class 60 and the average value of the control class 64.2. From the results of the comparison of the two sample classes, there was a difference in value of 3.7, so it can be concluded that there is no significant difference between the two pretest grades, meaning that the two classes have the same initial ability. Next, learning was conducted using mind mapping techniques in the experimental
\end{abstract}

Copyright (O2019, JRPD, ISSN 2615 - 1723 (Print), ISSN 2615 - 1766 (Online) 
class and learning without mind mapping techniques in the control class. After learning is given then in both classes posttest is conducted. For the experimental class obtained an average value of 82 and for the control class obtained an average value of 77.5. From the results of testing hypotheses with a significant level of 0.05 obtained a significant value of 0,000 because sig. $<\alpha$, the hypothesis is accepted, so it can be concluded that there is an effect of using mind mapping techniques on students' poetry writing skills in elementary school.

Keywords: Mind Mapping Techniques, Writing Skills, Poetry

\section{PENDAHULUAN}

Pembelajaran bahasa Indonesia adalah salah satu mata pelajaran yang diajarkan mulai dari sekolah dasar sampai perguruan tinggi. Ada beberapa aspek yang harus diperhatikan dalam pembelajaran bahasa Indonesia. Menurut Depdiknas (2006:317), ada empat aspek keterampilan, yaitu keterampilan mendengarkan atau menyimak, keterampilan berbicara, keterampilan membaca, dan keterampilan menulis. Keempat keterampilan tersebut tidak dapat dipisahkan dan saling berhubungan.

Salah satu aspek keterampilan dalam pembelajaran bahasa Indonesia yang harus dikuasai siswa yaitu keterampilan menulis. Keterampilan menulis merupakan komponen penggunaan bahasa yang harus diajarkan di sekolah dasar. Hal itu tersurat pada tujuan kurikulum tingkat satuan pendidikan yang bertujuan agar siswa memiliki kemampuan berkomunikasi secara efektif dan efisien sesuai dengan etika yang berlaku, baik secara lisan maupun tulis. Oleh karena itu, tujuan pembelajaran menulis diarahkan untuk siswa memiliki kegemaran menulis. Tarigan (dalam Taufina, 2015:229), mengatakan bahwa menulis adalah menurunkan atau melukiskan lambanglambang grafik yang menggambarkan suatu bahasa yang dipahami oleh seseorang, sehingga orang lain dapat membaca lambang-lambang grafik tersebut kalau mereka memahami bahasa dan gambaran grafik itu. Keterampilan menulis pada dasarnya harus dimiliki oleh semua siswa karena akan memudahkannya dalam menuangkan ide-ide yang dimiliki.

Di dalam Islam Allah SWT juga menganjurkan manusia untuk membaca dan menulis. Sebagaimana wahyu yang pertama kali diturunkan oleh Allah SWT yang memerintahkan kepada nabi Muhammad SAW untuk membaca dan menulis. Hal ini tergambar pada QS. Al-'Alaq ayat 1-5 :

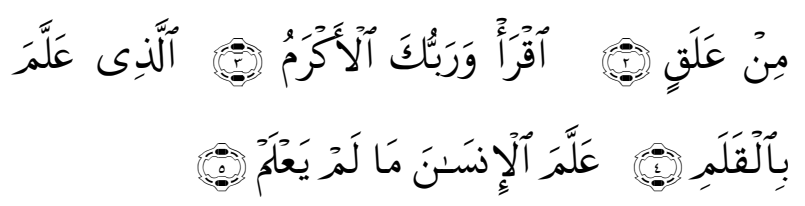

Artinya : "Bacalah dengan (menyebut) nama Tuhanmu yang menciptakan. Dia telah menciptakan manusia dari segumpal darah. Bacalah, dan Tuhanmu lah Yang Maha Pemurah. Yang mengajarkan (manusia) dengan perantaraan kalam. Dia mengajarkan kepada manusia apa yang tidak diketahuinya"'(Q.S Al-'Alaq : 1-5).

Berdasarkan ayat tersebut, jelaslah bahwa Allah SWT mengajar manusia dengan perantaraan baca tulis, sebab baca tulis adalah kunci ilmu. Membaca dan menulis adalah dua kegiatan yang saling berkaitan satu sama lainnya. Hal tersebut menunjukkan bahwa Islam sejak awal sudah menyerukan kepada manusia untuk membaca dan menulis, sebab wahyu Allah pun tidak bisa diterima tanpa dibaca terlebih dahulu, dan ia tak akan bisa dinikmati oleh generasi selanjutnya jika tidak ada dokumentasi dalam bentuk tulisan. Oleh karena itu, menulis merupakan kemampuan

Copyright $@ 2019$, JRPD, ISSN 2615 - 1723 (Print), ISSN 2615 - 1766 (Online) 
yang harus dimiliki oleh siswa untuk bisa menghasilkan karya-karyanya.

Selain itu, kemampuan lain yang harus dimiliki oleh siswa adalah kemampuan untuk bersastra. Kemampuan sastra perlu dimiliki oleh siswa sekolah dasar karena selain menyentuh sisi kognitif, pembelajaran sastra juga akan menyentuh sisi afektif siswa dengan nilai-nilai rasa yang ada di dalamnya. Sebagaimana Taufina (2015:277), yang mengatakan bahwa sastra dapat dikatakan sebagai bentuk upaya manusia untuk mengungkapkan gagasannya melalui bahasa yang lahir dari perasaan dan pemikirannya. Di sekolah dasar terdapat beberapa jenis karya sastra yang dapat dipelajari oleh siswa yaitu prosa, puisi, dan drama.

Puisi merupakan salah satu jenis karya sastra yang dipelajari. Taufina (2015:315), mengatakan bahwa puisi adalah bentuk karya sastra yang mengungkapkan pikiran dan perasaan penyair secara imajinatif dan disusun dengan mengonsentrasikan semua kekuatan bahasa dengan pengonsentrasian struktur fisik dan struktur batinnya. Puisi ini ditulis dalam bentuk larik-larik dan bait-bait. Pembelajaran puisi selain menambah kosa kata yang dimiliki siswa dalam pembelajaran bahasa Indonesia, juga dapat mengajarkan siswa tentang majas atau gaya bahasa yang sering digunakan di dalamnya. Selain itu juga merupakan sarana ekspresi rasa yang dimiliki siswa terhadap apa yang dirasa atau dilihatnya. Pembelajaran puisi terbagi pada pembelajaran menyimak, membaca, dan menulis puisi, dalam kaitannya dengan keterampilan menulis, puisi dapat dijadikan bahan untuk keterampilan menulis tersebut khususnya di kelas tinggi, karena di kelas tinggi siswa mulai diperkenalkan dengan karya-karya sastra tulisan dan dibiasakan untuk dapat menulis sebuah karya dengan sederhana.

Resmini, dkk (2007:137), mengatakan bahwa pembelajaran menulis di kelas tinggi sudah diarahkan dalam mengungkapkan gagasan faktual maupun imajinatif. Kegiatan menulis di kelas tinggi sudah dilaksanakan dalam bentuk pembuatan karangan imajinatif atau fiksi, karena siswa sudah memiliki keterampilan dasar menulis yang cukup. Siswa sudah dapat menulis dengan lancar. Resmini, dkk (2007:137), menambahkan beberapa materi menulis fiksi di kelas tinggi mencakup :

1) Menulis karangan berdasarkan rangkaian gambar seri, 2) melanjutkan cerita narasi, 3) menulis cerita rekaan berdasarkan pengalaman, 4) melanjutkan isi pantun, 5) menyusun karangan dari gambar seri yang diacak, 6) menulis prosa sederhana, 7) menulis puisi bebas, 8) memparafrasekan puisi, dan 9) menulis drama sederhana.

Dari uraian tersebut, menulis memiliki arti yang lebih khusus yaitu menuangkan pikiran dan perasaan ke dalam bentuk tulisan, itu artinya siswa diharapkan mampu membuat tulisan sebagai produk nyata dari pembelajaran bahasa fokus menulis yang bahannya berupa sebuah puisi. Pembelajaran

sastra di sekolah dasar merupakan bagian integral dari pembelajaran bahasa Indonesia. Sayangnya sastra yang merupakan bagian dari pelajaran bahasa Indonesia hanya dijadikan sebagai pelengkap atau selingan ketika guru menyampaikan pelajaran bahasa Indonesia, artinya sastra tidak mendapatkan porsi yang sesuai untuk disajikan di dalam kelas. Padahal sastra merupakan bagian tak terpisahkan dari pembelajaran bahasa Indonesia yang sejatinya mendapatkan porsi yang seimbang dengan pelajaran bahasa. Keterbatasan pembelajaran sastra di dalam kelas juga dipengaruhi oleh pemahaman dan kemampuan seorang guru dalam bersastra, tidak jarang guru ketika menyampaikan materi tentang sastra hanya memberikan teori-teori saja tanpa memberikan pengalaman langsung kepada siswa, padahal sastra bukanlah diajarkan sebatas teori tetapi memberikan pengalaman langsung bagi siswa. 
Selain itu saat kegiatan pembelajaran menulis puisi lebih cendrung bersifat teori informatif, bukan apresiatif produktif. Pembelajaran yang diciptakan guru hanya sebatas memberikan informasi pengetahuan tentang sastra saja sehingga kemampuan mengapresiasikan dan menciptakan sebuah karya belum dilakukan secara maksimal.

Hal yang akrab terjadi juga biasanya adalah penggunaan teknik pembelajaran puisi. Teknik yang digunakan untuk pembelajaran puisi biasanya ceramah. Dalam pembelajaran menulis puisi, penerapan satu teknik tidaklah dapat berjalan efektif untuk mengajarkan siswa menulis puisi, apalagi jika yang diajarkan hanyalah teori menulis puisi saja atau hanya membiarkan siswa menulis puisi bebas tanpa arahan atau variasi teknik dari guru, maka siswa akan enggan untuk menuangkan ideide kreatifnya di dalam sebuah tulisan.

Selain itu, dalam pembelajaran puisi, biasanya siswa hanya diminta untuk membaca contoh dari puisi yang terdapat di bukunya tanpa pernah diberikan kesempatan lebih luas untuk memahami puisi tersebut, kemudian biasanya kemampuan menulis siswa akan diukur dari jawaban yang ditulisnya berdasarkan pertanyaan-pertanyaan tentang isi puisi atau diminta untuk menyalin puisi, yang sebenarnya itu belumlah cukup untuk mengukur kemampuan/keterampilan siswa dalam menulis puisi.

Proses menulis yang ditemukan di sekolah dasar pun biasanya kurang diperhatikan. Kenyataannya, pada tahap pramenulis guru langsung menyuruh siswa untuk menulis puisi sesuai dengan keinginannya, sehingga proses menulis langsung pada tahap saat menulis. Sementara itu, pada tahap pasca menulis karya puisi siswa langsung dikumpulkan tanpa ada proses revisi. Padahal idealnya, proses menulis tersebut terdiri dari tiga tahap yaitu pramenulis, saat menulis, dan pasca menulis. Pada tahap pramenulis siswa diminta untuk menentukan tema puisi yang akan dibuat. Sehingga pada tahap saat menulis siswa dengan mudah menuangkan ide-idenya dengan baik. Sementara itu, pada tahap pasca menulis guru melakukan pemeriksaan (revisi) terhadap puisi yang ditulis siswa dan kemudian siswa diminta untuk membacakannya di depan kelas.

Oleh karena itu, untuk meningkatkan kemampuan menulis puisi siswa sekolah dasar dibutuhkan alternatif teknik pembelajaran yang lain agar kegiatan ini dapat berlangsung menyenangkan bagi siswa dan tetap mencapai tujuan pembelajaran. Teknik pembelajaran yang ditawarkan adalah teknik mengajar dengan mind mapping yang merupakan salah satu teknik yang sesuai diterapkan di dalam kelas supaya pembelajaran puisi lebih menarik bagi siswa.

Sejalan dengan hal tersebut Buzan (2013: 4) mengatakan bahwa :

Peta pikiran (mind mapping) adalah cara termudah untuk menempatkan informasi ke dalam otak dan mengambil informasi ke luar dari otak, mind mapping adalah cara mencatat yang kreatif, efektif, dan secara hafiah yang akan "memetakan" pikiran.

Dalam pembelajaran menulis puisi, siswa biasanya kesulitan dalam merangkaikan kata ke dalam baris-baris puisi. Oleh karena itu, dengan menggunakan teknik mind mapping ini diharapkan siswa mampu memetakan apa yang dipikirkannya ke dalam gambaran yang lebih tersusun, setelah terkumpul katakata dari proses pemetaan pikirannya, siswa dapat merangkaikan kata-kata tersebut dengan lebih mudah untuk menjadi sebuah puisi. Penerapan teknik mind mapping dalam pembelajaran menulis puisi pelajaran bahasa Indonesia akan membantu siswa untuk mengorganisir setiap kata yang dipikirkannya kemudian menyusunnya ke dalam baris-baris puisi. Mind mapping juga digunakan untuk menggeneralisasikan, memvisualisasikan serta mengklasifikasikan ide-ide dan sebagai bantuan dalam belajar, berorganisasi, pemecahan masalah, pengambilan keputusan serta dalam menulis. Dengan menggunakan teknik ini, kegiatan menulis puisi akan Copyright (2019, JRPD, ISSN 2615 - 1723 (Print), ISSN 2615 - 1766 (Online) 
sangat terbantu. Ide-ide yang dimiliki siswa akan lebih terorganisir untuk dapat dirangkaikan menjadi sebuah puisi. Menulis puisi akan disajikan dalam bentuk yang lebih dekat dan nyata bagi siswa, sehingga bukanlah sesuatu yang asing bagi siswa.

Menurut Istarani (2014:59), salah satu kelebihan dari mind mapping adalah dimungkinkan siswa untuk mengeluarkan ide atau gagasannya secara baik dan sistematis. Sehingga dengan penerapan teknik ini dapat lebih mengaktifkan ide-ide kreatif siswa dalam menulis karena pengorganisasian informasi yang dimiliki oleh otak akan lebih terarah dan tersusun dalam bentuk tulisan dengan lebih baik. Ciri khas mind mapping yang menggunakan gambar, warna, dan garis melengkung lebih sesuai dengan cara kerja otak dan akan lebih menarik untuk otak agar menghasilkan ide-ide kreatif dibandingkan dengan cara menulis konvensional yang hanya menggunakan kata dan garis-garis linear yang sebenarnya lebih membosankan dan kurang mengoptimalisasi kerja otak untuk berpikir dengan lebih kreatif.

Pembelajaran menggunakan teknik mind mapping dikonsep dengan melibatkan siswa untuk bisa memunculkan ide-ide terpendamnya yang dimulai dari titik tengah sehingga ia dapat mengembangkan ide-ide yang muncul tersebut. Sehingga dengan bermunculannya ide tersebut sangatlah membantu siswa dalam mengembangkan ide puisinya. Hal tersebut sesuai dengan pendapat Istarani (2014:55), yang menjelaskan bahwa mind mapping merupakan pembelajaran yang akan melatih alur pikir siswa menuju satu titik, dimana titik tersebut sebagai fokus suatu kajian. Kalau siswa dapat memfokuskan pikiran pada kajian itu, maka ia akan berkonsentrasi dan melakukan pembelajaran dengan baik sehingga siswa memiliki keterampilan dalam berpikir. Oleh karena itu, teknik mind mapping akan berpengaruh terhadap keterampilan menulis puisi.

\section{METODE PENELITIAN}

Penelitian ini dilakukan penelitian eksperimen yang merupakan penelitian yang dimaksud untuk mengetahui ada tidaknya akibat dari suatu yang dikenakan pada subjek selidik. Dengan kata lain penelitian eksperimen mencoba meneliti ada tidaknya hubungan sebab akibat. Penelitian eksperimen yang akan digunakan adalah penelitian Quasi Experimental Design.

Rancangan penelitian yang digunakan adalah Nonequivalent Control Group Design dengan melibatkan dua kelompok yaitu kelompok eksperimen dan kelompok kontrol. Menurut Sugiyono (2012:116), dalam desain ini terdapat dua kelompok tidak dipilih secara random, kemudian diberi pretest untuk mengetahui keadaan

\section{HASIL DAN PEMBAHASAN}

Sebelum kelas eksperimen dan kontrol diberikan perlakuan yang berbeda terlebih dahulu diberikan pretest untuk mengetahui kemampuan awal siswa. Kemudian diberikanlah perlakuan, yakni kelas eksperimen dengan menggunakan teknik mind mapping, sedangkan kelas kontrol tanpa menggunakan teknik mind mapping. Setelah keduanya diberi perlakuan dilakukan posttest untuk mengetahui kemampuan akhir siswa yang seterusnya akan dianalisis.

\section{Data Nilai Pretest}

Penelitian ini merupakan penelitian yang melibatkan dua kelas yang diberi perlakuan yang berbeda, yaitu kelas eksperimen diberi perlakuan dengan menggunakan teknik mind mapping dan kelas kontrol tanpa menggunakan teknik mind mapping. Pemilihan sampel dilakukan dengan teknik sampel jenuh (total sampling). Yang menjadi sampel dalam penelitian ini adalah siswa kelas $\mathrm{V}$.

Tabel di atas adalah data nilai pretest siswa pada kelas eksperimen dan kelas kontrol sebelum diberi perlakuan. Berdasarkan Tabel 4.1 terlihat bahwa rata-rata keterampilan Copyright (2019, JRPD, ISSN 2615 - 1723 (Print), ISSN 2615 - 1766 (Online) 
menulis puisi siswa kelas eksperimen $(\bar{x}=60)$ sedangkan siswa kelas $\operatorname{kontrol}(\bar{x}=64,2)$.

\section{Tabel. Data Nilai Pretest Kelas Sampel}

\begin{tabular}{|c|c|c|c|c|c|c|c|c|c|}
\hline \multirow[t]{2}{*}{$\mathbf{N}_{0}$} & \multirow[t]{2}{*}{ Kelas } & \multirow{2}{*}{$\begin{array}{l}\text { Jemiah } \\
\text { Stswa }\end{array}$} & \multicolumn{2}{|c|}{$\begin{array}{c}\text { Tuntas } \\
\text { es0) }\end{array}$} & \multicolumn{2}{|c|}{$\begin{array}{c}\text { TIdak Tuntas } \\
\text { (88) }\end{array}$} & \multirow{2}{*}{$\begin{array}{l}\text { Rata- } \\
\text { rata }\end{array}$} & \multirow[t]{2}{*}{$x_{\operatorname{man}}$} & \multirow[t]{2}{*}{$\mathbf{X}_{\text {min }}$} \\
\hline & & & Jumlah & $\%$ & Jumlah & $\%$ & & & \\
\hline 1 & Essperimen & 34 & 1 & 3 & 33 & 97 & 60 & 85 & 46 \\
\hline 2 & Kentrol & 36 & 1 & 3 & 35 & 97 & 64.2 & 85 & 54 \\
\hline
\end{tabular}

Keterangan :

$\mathrm{X}_{\max }=$ Nilai tertinggi

$\mathrm{X}_{\min }=$ Nilai terendah

Selanjutnya perolehan skor tertinggi dan terendah antara kelas eksperimen dan kelas kontrol memiliki skor yang berbeda pada skor terendah. Skor tertinggi siswa pada kelas eksperimen $\left(\mathrm{X}_{\max }=85\right)$ dan skor terendah $\left(\mathrm{X}_{\min }=\right.$ 46). Pada kelas kontrol skor tertinggi siswa $\left(\mathrm{X}_{\max }=85\right)$ dan skor terendah $\left(\mathrm{X}_{\min }=54\right)$. Berikut adalah diagram batang nilai pretest kelas eksperimen dan kelas kontrol.

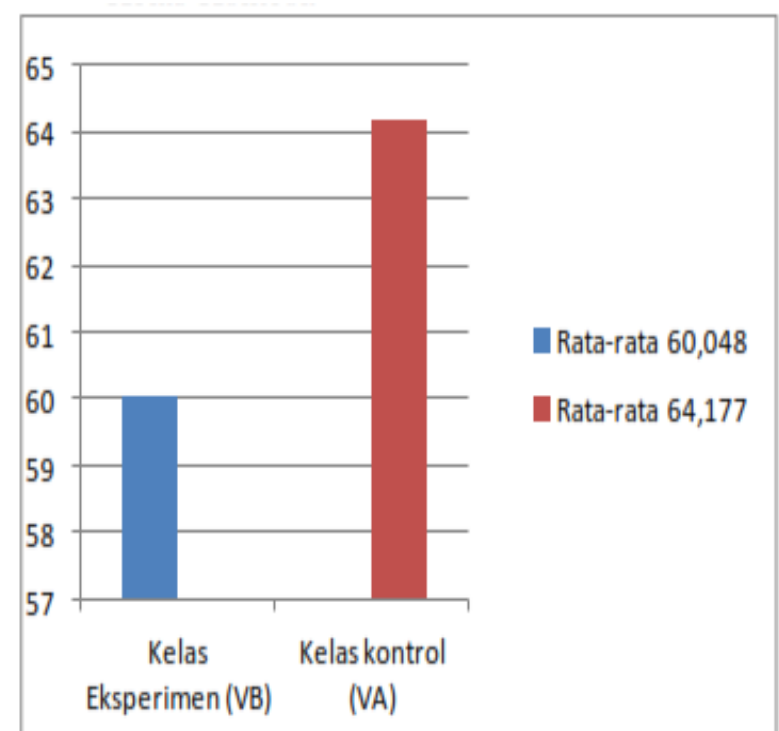

Gambar 1 Diagram Batang Nilai Pretest Kelas Eksperimen dan Kelas Kontrol.

Berdasarkan tabel 1 di atas, persentase ketuntasannya dapat digambarkan sebagai berikut :
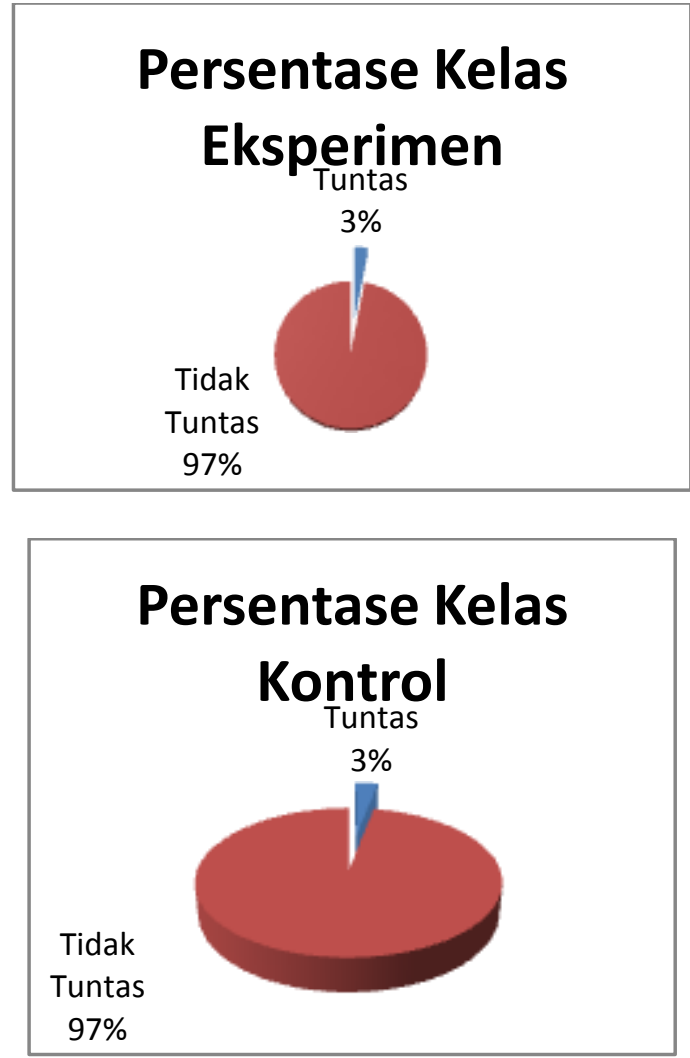

Gambar2 Diagram Persentase Ketuntasan Kelas Eksperimen dan Kontrol

\section{Data Nilai Posttest}

Setelah dilakukan pretest, di kelas eksperimen diberi perlakuan pembelajaran dengan menggunakan teknik mind mapping dan di kelas kontrol tanpa memberikan perlakuan. Dari perlakuan tersebut diperoleh nilai posttest kelas eksperimen dan kelas kontrol sebagai berikut :

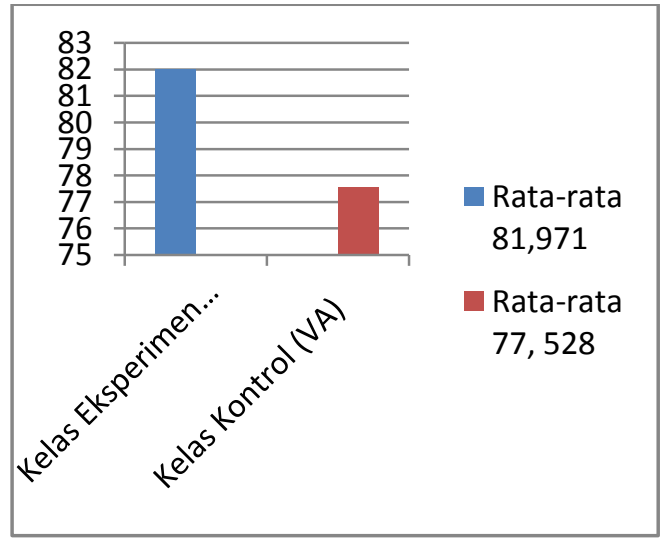

Gambar 3 Diagram Batang Nilai Posttest Kelas Eksperimen dan Kelas Kontrol.

Copyright $\odot 2019$, JRPD, ISSN 2615 - 1723 (Print), ISSN 2615 - 1766 (Online) 


\section{Perbandingan Data Nilai Pretest dan Posttest}

Berdasarkan deskripsi data nilai pretest dan posttest di atas, diperoleh ringkasan sebagai berikut :

\section{Ringkasan Data Nilai Pretest dan Posttest Siswa}

\begin{tabular}{|c|c|c|c|c|c|}
\hline \multirow{3}{*}{ No } & \multirow{3}{*}{ Aspek } & \multicolumn{4}{|c|}{ Kelas } \\
\hline & & \multicolumn{2}{|c|}{ Eksperimen } & \multicolumn{2}{|c|}{ Kentmol } \\
\hline & & Pretest & Pastint & Preter & Pestiest \\
\hline 1 & $X_{\text {main }}$ & 85 & 92 & 85 & 91 \\
\hline 2 & $\mathrm{X}_{\mathrm{min}}$ & 46 & 68 & 54 & 40 \\
\hline 3 & Ratr-rata & 60 & 82 & 64.2 & 77.5 \\
\hline 4 & Jumlah Kctuntasan & 1 Orang & 22 Orang & 1 Orang & 16 Orang \\
\hline 5 & Persentase Ketuntasan & $3 \%$ & $65 \%$ & $3 \%$ & $44 \%$ \\
\hline
\end{tabular}

\section{SIMPULAN}

Dari hasil analisis yang dilakukan dalam penelitian ini diperoleh kesimpulan bahwa keterampilan menulis puisi siswa setelah diberikan perlakuan mengalami peningkatan sehingga penggunaan teknik mind mapping berpengaruh terhadap keterampilan menulis puisi siswa sekolah dasar. Hal ini dapat dilihat dari rata-rata keterampilan menulis puisi siswa pada hasil posttest (tes akhir) kelas eksperimen yang menggunakan teknik mind mapping adalah 82 , sedangkan rata-rata keterampilan menulis puisi siswa pada kelas kontrol adalah 77,5 dengan perbandingan nilai sebesar 4,4.

Selain itu, dapat dilihat juga dari hasil perhitungan uji hipotesis dengan menggunakan aplikasi SPSS 21 diperoleh hasil nilai signifikan sebesar 0,000. Berdasarkan nilai signifikan tersebut berarti sig $<\alpha(0,000<0,05)$. Artinya adalah tolak $H_{0}$ terima $H_{1}$. Jadi, dapat disimpulkan bahwa $\mathrm{H}_{0}$ ditolak dan $\mathrm{H}_{1}$ diterima, yaitu dengan artian "Keterampilan menulis puisi siswa yang menggunakan teknik pembelajaran mind mapping lebih baik dari pada siswa yang tidak menggunakan teknik pembelajaran mind mapping (terdapat pengaruh)".

Untuk meningkatkan keterampilan menulis puisi siswa di sekolah dasar pendidik dapat menerapkan atau mengimplementasikan teknik mind mapping sebagai kiat dalam pembelajaran agar ide-ide ataupun gagasan bisa muncul dari peserta didik.

\section{DAFTAR PUSTAKA}

Buzan, Tony. (2013). Buku Pintar Mind Map. Jakarta : Gramedia Pustaka Utama.

Departemen Pendidikan Nasional. (2006). Kurikulum Tingkat Satuan Pendidikan. Jakarta : Depdiknas.

Istarani. (2014). 58 Model Pembelajaran Inovatif. Medan : Media Persada.

Resmini. (2007). Pendidikan Bahasa \& Sastra Indonesia di Kelas Tinggi. Bandung : UPI Press.

Sugiyono. (2012). Metode Penelitian Pendidikan (Pendekatan Kuantitatif, Kualitatif, dan $R \& D$. Bandung : Alfabeta.

Taufina. (2015). Keterampilan Berbahasa dan Apresiasi Sastra Indonesia di SD.Padang : Sukabina Press. 